TITLE:

\title{
Hydrogen desorption property of mechanically prepared nanostructured graphite
}

\section{AUTHOR(S):}

Orimo, S; Matsushima, T; Fujii, H; Fukunaga, T; Majer, $G$

\section{CITATION:}

Orimo, S ... [et al]. Hydrogen desorption property of mechanically prepared nanostructured graphite. JOURNAL OF APPLIED PHYSICS 2001, 90(3): 1545-1549

\section{ISSUE DATE:}

2001-08-01

URL:

http://hdl.handle.net/2433/39702

\section{RIGHT:}

Copyright 2001 American Institute of Physics. This article may be downloaded for personal use only. Any other use requires prior permission of the author and the American Institute of Physics. 


\title{
Hydrogen desorption property of mechanically prepared nanostructured graphite
}

\author{
S. Orimo, ${ }^{\text {a) }}$ T. Matsushima, and H. Fujii \\ Faculty of Integrated Arts and Sciences, Hiroshima University, Higashi-Hiroshima 739-8521, Japan \\ T. Fukunaga \\ Research Reactor Institute, Kyoto University, Osaka 590-0494, Japan \\ G. Majer \\ Max-Planck-Institut für Metallforschung, Heisenbergstrasse 1, 70569 Stuttgart, Germany
}

(Received 29 January 2001; accepted for publication 21 May 2001)

Two desorption peaks of hydrogen molecule (mass number=2), starting at about 600 and $950 \mathrm{~K}$, respectively, are observed in thermal desorption mass spectroscopy of nanostructured graphite mechanically milled for $80 \mathrm{~h}$ under hydrogen atmosphere. It follows from a combined analysis of thermal desorption mass spectroscopy and thermogravimetry, that $\sim 6$ mass $\%$ of hydrogen (corresponding to $80 \%$ of the total amount of hydrogen) is desorbed at the first desorption peak as a mixture of pure hydrogen and hydrocarbons. Below the temperature of the second desorption peak, at which recrystallization related desorption occurs, nanostructured graphite is expected to retain its specific defective structures mainly with carbon dangling bonds as suitable trapping sites for hydrogen storage. The formation process of the nanostructures during milling under hydrogen atmosphere is also discussed on the basis of the profile of Raman spectroscopy. (C) 2001 American Institute of Physics. [DOI: 10.1063/1.1385362]

\section{INTRODUCTION}

Motivated by the report by Dillon et al., ${ }^{1}$ much attention has recently been directed towards the use of single- (multi-) walled carbon nanotubes for hydrogen storage. ${ }^{2-10}$ Some of the reports on relationships between structures of the nanotubes and hydrogen storage capabilities focus mainly on capillary effects of (bundles of) nanotubes. A capillary effect is achieved first by "opening the nanotube cap" by pretreatments such as chemical etching, partial oxidation, and/or supersonic wave methods, and second by trying to put the hydrogen molecule into the capillary. The pretreatments prior to hydrogenation, however, seem not only to open the cap but also to increase the number of defects like carbon dangling bonds, even in side walls of the carbon nanotubes. ${ }^{11}$ (Besides the nanotubes, graphite nanofibers, ${ }^{12-16}$ i.e., stacking of small platelet graphite, have a large number of defects at the geometrical edge area of platelets.) Therefore, hydrogen storage capabilities that are enhanced by defective structures should be taken into account in carbon-related materials.

So far, the hydrogen solubility, diffusivity, and thermal desorption properties of graphite with defective structures have been extensively investigated experimentally ${ }^{17-40}$ and theoretically, ${ }^{37,41-44}$ mainly from the viewpoint of the development of nuclear fusion materials. Here, the defects, which will act as hydrogen trapping sites, are experimentally formed by electron/neutron/ion irradiation methods. ${ }^{45-55}$

One of the other effective methods for preparing defective structures of carbon-related materials is mechanical

a)Electronic mail: orimo@hiroshima-u.ac.jp milling. ${ }^{56-67}$ This primitive, but reliable, method may provide a new category of carbon-related materials for hydrogen storage, in which hydrogen is suitably chemisorbed by the defective structures. On the basis of this, we have been focusing on the hydrogen storage capabilities in defective carbon-related materials prepared by mechanical milling.

In a previous report, ${ }^{68}$ we reported fundamental investigations of the structures and hydrogen concentrations in nanostructured graphite prepared by mechanical milling under hydrogen atmosphere. After expansion of the graphite inter layer, the long-range ordering of the inter layer disappears continuously with increasing milling time. The hydrogen concentration, precisely determined by oxygen combustion analysis, reaches up to 7.4 mass \% $\left(\mathrm{CH}_{0.95}\right)$ after milling for $80 \mathrm{~h}$, as is shown in Fig. 1. The results of systematic neutron diffraction measurements and transmission electron microscopy (TEM) observations of the samples have been also reported by Fukunaga et al. ${ }^{69}$ and by Tanabe et al. ${ }^{70}$ respectively.

The main purpose of the present work is to clarify the thermal desorption (dehydriding) property of nanostructured graphite using a sample mechanically milled for $80 \mathrm{~h}$. Prior to the thermal desorption experiments, we also investigated the formation process of the nanostructures in graphite during milling under hydrogen atmosphere using Raman spectroscopy.

\section{EXPERIMENT}

\section{A. Sample preparation}

We used $300 \mathrm{mg}$ of high-purity graphite powder (99.997\% purity, $\sim 200 \mu \mathrm{m}$ ) as a host sample and 20 steel 


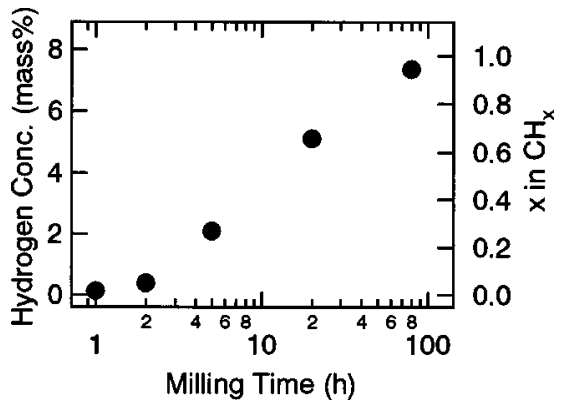

FIG. 1. Total hydrogen concentration in nanostructured graphite as a function of milling time under hydrogen atmosphere (see Ref. 68).

balls $7 \mathrm{~mm}$ in diameter were placed in a steel vial $30 \mathrm{cc}$ in volume. The material and shape of the vial for mechanical milling were selected carefully, so as to minimize the amount of elemental $\mathrm{Fe}$ contaminated during mechanical milling. ${ }^{71-73}$ The vial was equipped with a connection valve for evacuation and introduction of hydrogen. This was used to directly degas the host sample for $12 \mathrm{~h}$ below 1 $\times 10^{-4} \mathrm{~Pa}$ using a turbomolecular pump. High-purity hydrogen $(99.99999 \%$ purity) or deuterium (99.99\% purity) of 1.0 MPa was then introduced as an initial pressure. The host sample was mechanically milled using the planetary ball mill apparatus (Fritsch P7) at $400 \mathrm{rpm}$ for periods of $1-80 \mathrm{~h}$ at room temperature. Before and after milling, all samples were handled in a glovebox filled with purified argon to minimize oxidation and water adsorption.

\section{B. Sample characterization}

The samples thus prepared were examined by Raman spectroscopy (a Nicolet, Almega-HD, $532 \mathrm{~nm}$ laser with backscattering geometry), thermal desorption mass spectroscopy (TDS) (Anelva M-QA200TS), thermogravimetry (TG) and differential thermal analysis (DTA) (Seiko TG-DTA TG8120), and X-ray diffraction (XRD) measurements (Mac Science MXP3, with $\mathrm{Cu} K \alpha$ radiation). The apparatus for the mass spectroscopy was specially designed and built for use inside the glovebox, and permitted simultaneous measurements of TG and DTA without exposing the samples to air.

\section{RESULTS AND DISCUSSION}

Figure 2 shows profiles of Raman spectroscopy of the nanostructured graphite during milling under hydrogen atmosphere. The peak at $1580 \mathrm{~cm}^{-1}$ in the host sample corresponds to the in-layer vibration $\left(E_{2 g}, g\right)$ mode of graphite. ${ }^{74-78}$ After $1 \mathrm{~h}$ of milling, however, typical disordered $\left(d\right.$ and $\left.d^{\prime}\right)$ modes originating from defects are observed both at 1360 and $1610 \mathrm{~cm}^{-1} .^{74-78}$ The $d$ and $d^{\prime}$ modes are enhanced with increasing milling time, indicating an increase in the number of defects upon milling. Although two peaks, the $g$ mode at $1580 \mathrm{~cm}^{-1}$ and the $d^{\prime}$ mode at $1610 \mathrm{~cm}^{-1}$, overlap after milling for 20 and $80 \mathrm{~h}$, these peaks are separated by a Lorenzian approximation, as is shown in Fig. 2. The increase of the peak widths, especially noticeable between 5 and $20 \mathrm{~h}$, indicates a decrease of the degree of graphitization of the samples.

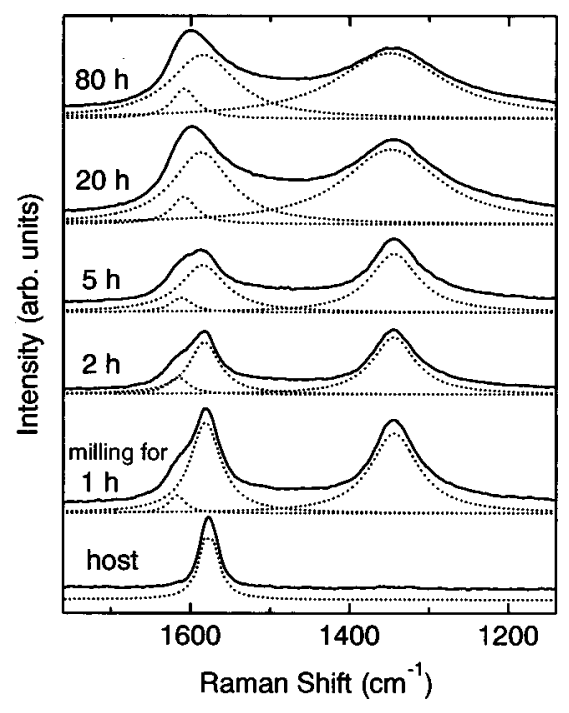

FIG. 2. Variation of the Raman spectrum of nanostructured graphite mechanically milled under hydrogen atmosphere. The dotted lines indicate the separate vibration modes. The background of the original profiles and that of the simulations is shifted for clarity.

The variation of the in-layer crystallite sizes, $L_{a}$, upon milling was estimated from the intensity ratio of the two Raman peaks, $I_{1360} / I_{1580} \cdot{ }^{79-81}$ The result is given in Table I, together with the interlayer crystallite sizes, $L_{c}$, estimated by $\mathrm{x}$-ray diffraction profiles [(002) diffraction] of the same samples. ${ }^{68}$ The value $L_{a}$ decreases strongly at the very beginning of the milling, while variation of the value $L_{c}$ is small. These results indicate that the milling process leads to nanocrystallization first along the direction perpendicular to the basal plain of graphite (cuttingly milling), and then parallel to the basal plain (cleavingly milling), ${ }^{82}$ although the data from Raman spectroscopy are mainly from the surface area of the samples. The crystallite sizes, less than $4 \mathrm{~nm}$, after milling for $80 \mathrm{~h}$, are similar to those estimated from neutron diffraction data of nanostructured graphite mechanically milled under argon atmosphere. ${ }^{69}$

As shown in Fig. 1, the total hydrogen concentration increases with decreasing crystallite size, accompanied by an increase in the number of the defects. The concentration reaches 7.4 mass \% $\left(\mathrm{CH}_{0.95}\right)$ after milling for $80 \mathrm{~h}$, and this value is comparable to the hydrogen concentration that can be stored in carbon nanotubes ${ }^{1,3}$ and also in conventional (super-) activated carbon ${ }^{83-86}$ at temperatures below $100 \mathrm{~K}$ and hydrogen pressures about $5 \mathrm{MPa}$.

TABLE I. In-layer crystallite size, $L_{a}$, estimated by the intensity ratio of the two Raman peaks, and interlayer crystallite size, $L_{c}$, estimated by the width of the x-ray diffraction profile (reported in Ref. 68).

\begin{tabular}{ccc}
\hline \hline $\begin{array}{c}\text { Milling time } \\
\text { under hydrogen } \\
(\mathrm{h})\end{array}$ & \multicolumn{2}{c}{ Crystallite size $(\mathrm{nm})$} \\
\cline { 2 - 3 } & In-layer, $L_{a}$ & Interlayer, $L_{c}$ \\
\hline 0 & $\cdots$ & 60 \\
1 & $\sim 5$ & 50 \\
2 & $\sim 4$ & 40 \\
$5-80$ & $<4$ & $\ldots$ \\
\hline \hline
\end{tabular}



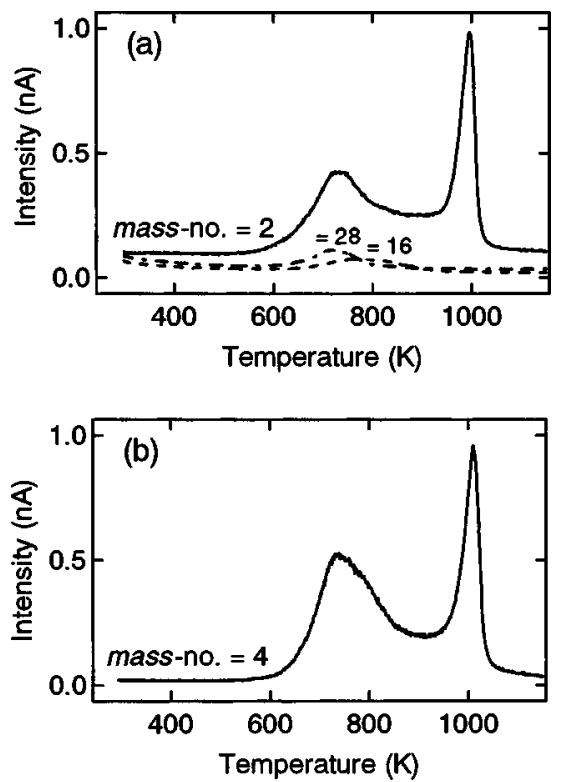

FIG. 3. TDS of nanostructured graphite mechanically milled under hydrogen (a) and deuterium (b) atmospheres, respectively.

The specific surface area of the sample after milling for $80 \mathrm{~h}$ was only of the order of $10 \mathrm{~m}^{2} / \mathrm{g},{ }^{68}$ suggesting that the amount of hydrogen coming from the surface area is rather small compared to the total hydrogen concentration.

The sample obtained after milling for $80 \mathrm{~h}$ was also investigated by thermal desorption mass spectroscopy to clarify the dehydriding property of the mechanically prepared nanostructured graphite. The results are shown in Fig. 3 (a). We found that there are two desorption peaks with mass number $=2$, starting at about 600 and $950 \mathrm{~K}$, respectively. These desorption phenomena are also reproducible in the sample mechanically milled under deuterium atmosphere, shown in Fig. 3(b). This confirms that the hydrogen has been stored inside the nanostructured graphite, and it is not coming from adsorbed water or other hydrogen sources. At temperatures around the first desorption peak in Fig. 3(a), small traces of the desorption peaks of hydrocarbons with mass number $=16$ from $\mathrm{CH}_{4}$ and 28 from a fragment of $\mathrm{C}_{2} \mathrm{H}_{6}$ were also detected. We checked, however, that the fraction from the hydrocarbons is only less than $1 \%$ in the desorption peak area with mass number $=2$ in Fig. 3(a). Furthermore, no hydrocarbon has been found at temperatures where the second desorption peak appears.

In our opinion, the first desorption peak in Fig. 3(a) has a similar origin to that of the main desorption peaks of hydrogen from single-walled carbon nanotubes, which has been reported recently by Dillon et al. ${ }^{87}$ and by Hirscher et al..$^{88,89}$ (Here the apparent desorption temperatures tend to be modified by "kinetics" effects, depending on the amount of metallic impurities, heating rates, etc.) In addition, hydrogen desorption from amorphous-carbon films, so called diamondlike carbons with $\mathrm{CH}_{2}$ and/or $\mathrm{CH}_{3}$ coordination, ${ }^{90-92}$ has been detected at temperatures similar to that of the first desorption peak in Fig. 3(a). Partial formation of $\mathrm{CH}_{3}$ coordination with the $s p^{3}$ bond, originating from defective structures of the nanostructured graphite, is also suggested by the

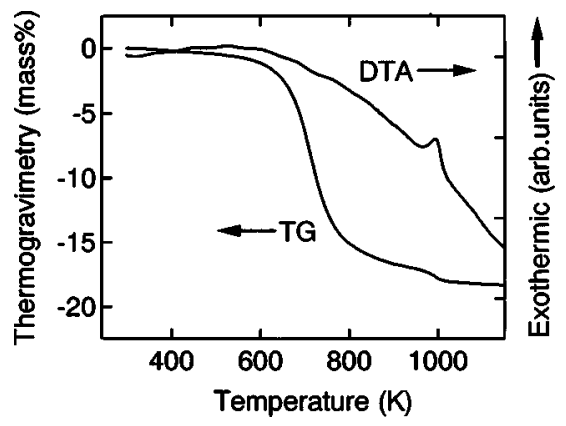

FIG. 4. TG and DTA profiles of nanostructured graphite mechanically milled under hydrogen atmosphere.

increase of the background signal around $1525 \mathrm{~cm}^{-1}$ in the Raman spectroscopy spectra, ${ }^{75,76,93,94}$ as shown in Fig. 2.

Thermogravimetry and differential thermal analysis profiles were simultaneously obtained during the TDS measurement, and the results are shown in Fig. 4.

In the TG profile, there are two mass reductions, 16 and 1.5 mass \%, corresponding to the two desorption peaks of the TDS profile in Fig. 3(a). The first reduction is due to the desorption of both hydrogen and hydrocarbons, and the second one is due only to hydrogen. The oxygen combustion method indicates that the total hydrogen concentration is 7.4 mass $\%$ in the sample mechanically milled for $80 \mathrm{~h},{ }^{68}$ as shown in Fig. 1. Thus, $\sim 6$ mass $\%$ of hydrogen, that is, $80 \%$ of the total hydrogen, is estimated to be desorbed in the first desorption peak of the TDS profile in Fig. 3(a) as a mixture of pure hydrogen and hydrocarbons.

In the DTA profiles, there is an exothermic peak around $1000 \mathrm{~K}$, corresponding to the temperature of the second desorption peak. However, neither an endo- nor an exothermic peak has been observed at the temperature of the first desorption peak (see Fig. 4). According to the Kissinger plot, ${ }^{95}$ which is shown in Fig. 5, the activation enthalpy of the exothermic peak around $1000 \mathrm{~K}$ is calculated to be $244 \mathrm{~kJ} / \mathrm{mol}$. This value agrees well with the activation enthalpy for recrystallization of nanostructured graphite, ${ }^{60}$ indicating that the second desorption peak, where only hydrogen is desorbed, is induced by recrystallization of the nanostructured graphite. Hydrogen desorption induced by recrystallization has also been detected in diamond-like carbon. ${ }^{90}$ The value

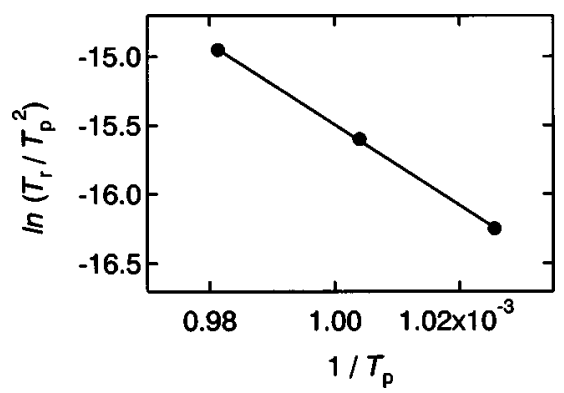

FIG. 5. Kissinger plot of the exothermic peak around $1000 \mathrm{~K}$ detected by the differential thermal analysis shown in Fig. 4. Notations $T_{r}$ and $T_{p}$ indicate the heating rates $(5,10$ and $20 \mathrm{~K} / \mathrm{min})$ and peak temperatures $(975,996$ and $1019 \mathrm{~K}$ ), respectively. The solid line represents a least square fitting of the data. 


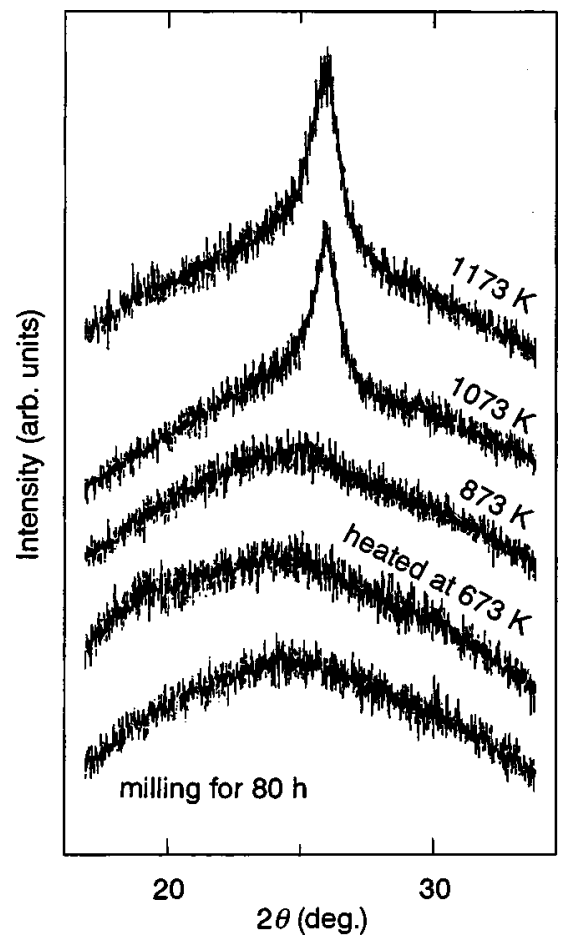

FIG. 6. XRD profiles of the nanostructured graphite: as milled without heat treatment (bottom) and heat treated at temperatures of 673, 873, 1073, and $1173 \mathrm{~K}$.

$244 \mathrm{~kJ} / \mathrm{mol}$ agrees with the activation enthalpy for hydrogen diffusion in graphite, ${ }^{24,25,27}$ and, moreover, no exothermic peak around $1000 \mathrm{~K}$ is detected in the nanostructured graphite prepared by mechanical milling under argon atmosphere. These experimental results suggest that the nanostructure of graphite prepared under hydrogen clearly differs from that under argon, and also that the recrystallization induced by hydrogen desorption might be promoted around the second desorption peak.

XRD profiles after heat treatments were measured to confirm the recrystallization of the nanostructured graphite around $1000 \mathrm{~K}$, as is shown in Fig. 6. The (002) diffraction peak corresponding to ordering of the interlayer of graphite can be observed in the sample heated at $1073 \mathrm{~K}$. This is consistent with the above results, confirming that the second desorption peak is related to the recrystallization of the nanostructured graphite. In other words, at temperatures below the second desorption peak, nanostructured graphite is expected to retain its specific defective structures as suitable trapping sites for hydrogen storage.

Preliminary results of Raman spectroscopy suggest that the nanostructures are not affected by the heat treatments, at least below the second desorption peak around $1000 \mathrm{~K}$.

To improve the hydrogen storage capabilities of mechanically prepared nanostructured graphite, it is necessary to lower the temperature of the first desorption peak and also to lower the fraction of hydrocarbon formation. Modified electrical structures ${ }^{96,97}$ caused by the formation of the nanostructures in graphite will be also investigated.

\section{SUMMARY}

The formation process of nanostructures in graphite during milling under hydrogen atmosphere was examined using Raman spectroscopy. The milling process leads to nanocrystallization first along the direction perpendicular to the basal plain of graphite (cuttingly milling), and second parallel to the basal plain (cleavingly milling). The crystallite size after milling for $80 \mathrm{~h}$ is estimated to be $4 \mathrm{~nm}$. In this sample with hydrogen concentration of 7.4 mass \% $\left(\mathrm{CH}_{0.95}\right)$, there were two desorption peaks of the hydrogen molecule, starting from $\sim 600$ and $950 \mathrm{~K}$, respectively. These desorption phenomena are also reproducible in the sample mechanically milled under deuterium atmosphere, indicating that the desorption peaks represent the hydrogen (deuterium) inside nanostructured graphite, and are not from adsorbed water or other hydrogen sources. The combined analysis of thermal desorption mass spectroscopy and thermogravimetry indicates that $\sim 6$ mass $\%$ of hydrogen (corresponding to $80 \%$ of the total amount of hydrogen) is desorbed at the first desorption peak as a mixture of pure hydrogen and hydrocarbons. The data indicate that nanostructured graphite retains its specific defective structures with mainly carbon dangling bonds as suitable trapping sites for hydrogen storage below about $950 \mathrm{~K}$.

\section{ACKNOWLEDGMENTS}

The authors are very grateful to Professor H. Atsumi for his critical reading of the manuscript, and also to Dr. A. Züttel, Dr. M. Hirscher and Professor Y. Kitano for their valuable discussion and suggestions. This work was financially supported by the New Energy and Industrial Technology Development Organization (NEDO), Industrial Technology Research Grant Program in 2000, by the Ministry of Education, Science, Sports and Culture, Grant-in-Aid for Scientific Research on Priority Areas and on COE (13CE202), and by the Deutsche Forschungsgemeinschaft (DFG).

${ }^{1}$ A. C. Dillon, K. M. Jones, T. A. Bekkedahl, C. H. Kiang, D. S. Bethune, and M. J. Heben, Nature (London) 386, 377 (1997).

${ }^{2}$ Ch. Nützenadel, A. Züttel, D. Chartouni, and L. Schlapbach, Electrochem. Solid-State Lett. 2, 30 (1998); also a detailed description of recent studies on hydrogen sorption by carbon nanotubes and other carbon nanostructures is summarized in the following: A. Züttel, Ch. Nützenadel, P. Sudan, $\mathrm{Ph}$. Mauron, Ch. Emmenegger, S. Rentsch, L. Schlapbach, A. Weidenkaff, and T. Kiyobayashi, J. Alloys Compd. (in press).

${ }^{3}$ Y. Ye, C. C. Ahn, C. Witham, B. Fultz, J. Liu, A. G. Rinzler, D. Colbert, K. A. Smith, and R. E. Smalley, Appl. Phys. Lett. 74, 2307 (1999).

${ }^{4}$ P. Chen, X. Wu, J. Lin, and K. L. Tan, Science 285, 91 (1999).

${ }^{5}$ C. Liu, Y. Y. Fan, M. Liu, H. T. Cong, H. M. Cheng, and M. S. Dresselhaus, Science 286, 1127 (1999).

${ }^{6}$ F. Darkrim and D. Levesque, J. Phys. Chem. B 104, 6773 (2000).

${ }^{7}$ N. Rajalakshmi, K. S. Dhathathreyan, A. Govindaraj, and B. C. Satishkumar, Electrochim. Acta 45, 4511 (2000).

${ }^{8}$ S. M. Lee et al., Synth. Met. 113, 209 (2000).

${ }^{9}$ R. T. Yang, Carbon 38, 623 (2000).

${ }^{10}$ X. B. Wu, P. Chen, J. Liu, and K. L. Tan, Int. J. Hydrogen Energy 25, 261 (2000).

${ }^{11}$ M. Monthioux, B. W. Smith, B. Burteaux, A. Claye, J. E. Fischer, and D. E. Luzzi, Carbon 39, 1251 (2001).

${ }^{12}$ A. Chambers, C. Park, R. T. K. Baker, and N. M. Rodriguez, J. Phys. Chem. B 102, 4253 (1998).

${ }^{13}$ C. C. Ahn, Y. Ye, B. V. Ratnakumar, C. Witham, R. C. Bowman, Jr., and B. Fultz, Appl. Phys. Lett. 73, 3378 (1998). 
${ }^{14}$ Y. Y. Fan, B. Liao, M. Liu, Y. L. Wei, M. Q. Lu, and H. M. Cheng, Carbon 37, 1649 (1999)

${ }^{15}$ R. Ströbel, L. Jörissen, T. Schliermann, V. Trapp, W. Shütz, K. Bohmhammel, G. Wolf, and J. Garche, J. Power Sources 84, 221 (1999).

${ }^{16}$ B. K. Gupta and O. N. Srivastava, Int. J. Hydrogen Energy 25, 825 (2000).

${ }^{17}$ W. R. Wampler, D. K. Brice, and C. W. Magee, J. Nucl. Mater. 63, 415 (1967).

${ }^{18}$ H. D. Röhrig, P. G. Fischer, and R. Hecker, J. Am. Ceram. Soc. 59, 316 (1976).

${ }^{19}$ R. A. Causey, T. S. Elleman, and K. Verghese, Carbon 17, 323 (1979).

${ }^{20}$ P. Hucks, K. Flaskamp, and E. Vietzke, J. Nucl. Mater. 93-94, 558 (1980).

${ }^{21}$ J. Roth, B. M. U. Scherzer, R. S. Blewer, D. K. Brice, S. T. Picraux, and W. R. Wampler, J. Nucl. Mater. 93-94, 601 (1980).

${ }^{22}$ K. Sone and G. M. MacCracken, J. Nucl. Mater. 111-112, 606 (1982).

${ }^{23}$ K. Ashida, K. Ichimura, M. Matsuyama, and K. Watanabe, J. Nucl. Mater. 128-129, 792 (1984).

${ }^{24}$ R. A. Causey and K. L. Wilson, J. Nucl. Mater. 138, 57 (1986).

${ }^{25}$ R. A. Causey, M. I. Baskes, and K. L. Wilson, J. Vac. Sci. Technol. A 4, 1189 (1986).

${ }^{26}$ K. Ashida, K. Ichimura, M. Matsuyama, and K. Watanabe, J. Nucl. Mater. 148, 217 (1987).

${ }^{27}$ H. Atsumi, S. Tokura, and M. Miyake, J. Nucl. Mater. 155-157, 241 (1988).

${ }^{28}$ W. Möller, J. Nucl. Mater. 162-164, 138 (1989).

${ }^{29}$ W. R. Wampler, B. L. Doyle, R. A. Causey, and K. Wilson, J. Nucl. Mater. 176-177, 983 (1990).

${ }^{30}$ R. A. Causey, W. R. Wampler, and D. Walsh, J. Nucl. Mater. 176-177, 987 (1990).

${ }^{31}$ E. Hoinkis, J. Nucl. Mater. 182, 93 (1991); 183, 9 (1991).

${ }^{32}$ U. Kürpick, G. Meister, and A. Goldmann, Appl. Phys. A: Solids Surf. 55, 529 (1992).

${ }^{33}$ H. Atsumi, M. Iseki, and T. Shikama, J. Nucl. Mater. 191-194, 368 (1992).

${ }^{34}$ S. Chiu and A. A. Haasz, J. Nucl. Mater. 210, 34 (1994).

${ }^{35} \mathrm{H}$. Atsumi, M. Iseki, and T. Shikama, J. Nucl. Mater. 212-215, 1478 (1994).

${ }^{36}$ P. Franzen and E. Vietzke, J. Vac. Sci. Technol. A 12, 820 (1994).

${ }^{37}$ A. A. Haasz, P. Franzen, J. W. Davis, S. Chiu, and C. S. Pitcher, J. Appl. Phys. 77, 66 (1995).

${ }^{38}$ J. W. Davis and A. A. Haasz, J. Nucl. Mater. 220-222, 832 (1995).

${ }^{39}$ H. Atsumi, M. Iseki, and T. Shikama, J. Nucl. Mater. 233-237, 1128 (1996)

${ }^{40}$ Y. Gotoh, J. Nucl. Mater. 248, 46 (1997).

${ }^{41}$ A. J. Bennett, B. Mccarroll, and R. P. Messmer, Surf. Sci. 24, 191 (1971).

${ }^{42}$ R. Dovesi, C. Pisani, F. Ricca, and C. Roetti, Surf. Sci. 72, 140 (1978).

${ }^{43}$ S. Aronowitz and S. Chang, Astrophys. J. 293, 243 (1985).

${ }^{44}$ S. L. Kanashenko, A. E. Gorodetsky, V. N. Chernikov, A. V. Markin, A. P. Zakharov, B. L. Doyle, and W. R. Wampler, J. Nucl. Mater. 233-237, 1207 (1996).

${ }^{45}$ K. Niwase, Phys. Rev. B 52, 15785 (1995).

${ }^{46}$ T. Venkatesan, B. S. Elman, G. Braunstein, M. S. Dresselhaus, and G. Dreselhaus, J. Appl. Phys. 56, 3232 (1984).

${ }^{47}$ B. T. Kelly, J. Vac. Sci. Technol. A 4, 1171 (1986).

${ }^{48}$ H. Shimizu, S. Suginuma, and Y. Gotoh, J. Nucl. Mater. 176-177, 1000 (1990).

${ }^{49}$ H. J. Steffen, D. Marton, and J. W. Rabalais, Phys. Rev. Lett. 68, 1726 (1992).

${ }^{50}$ H. J. Steffen, C. D. Roux, D. Marton, and J. W. Rabalais, Phys. Rev. B 44, 3981 (1991)

${ }^{51}$ T. Tanabe, S. Muto, and K. Niwase, Appl. Phys. Lett. 61, 1638 (1992).

${ }^{52}$ E. Asari, I. Kamioka, K. Nakamura, T. Kawabe, W. A. Lewis, and M. Kitajima, Phys. Rev. B 49, 1010 (1994).

${ }^{53}$ M. Kitajima, E. Asari, and K. Nakamura, J. Nucl. Mater. 212-215, 139 (1994).

${ }^{54}$ S. Muto and T. Tanabe, Philos. Mag. A 76, 679 (1997).

${ }^{55}$ M. Takeuchi, S. Muto, T. Tanabe, H. Kurata, and K. Hojou, J. Nucl. Mater. 271-272, 280 (1999).
${ }^{56}$ M. Nakamizo, H. Honda, and M. Inagaki, Carbon 16, 281 (1978).

${ }^{57}$ L. Nikiel and P. W. Jagodzinski, Carbon 31, 1313 (1993).

${ }^{58}$ K. Niwase, T. Tanaka, Y. Kakimoto, K. N. Ishihara, and P. H. Shingu, Mater. Trans., JIM 36, 282 (1995).

${ }^{59}$ T. D. Shen, W. Q. Ge, K. Y. Wang, M. X. Quan, J. T. Wang, W. D. Wei, and C. C. Koch, Nanostruct. Mater. 7, 393 (1996).

${ }^{60}$ J. Tang, W. Zhao, L. Li, A. U. Falster, W. B. Simmons, Jr., W. L. Zhou, Y. Ikuhara, and J. H. Zhang, J. Mater. Res. 11, 733 (1996).

${ }^{61}$ T. Fukunaga, K. Nagano, U. Mizutani, H. Wakayama, and Y. Fukushima, J. Non-Cryst. Solids 232-234, 416 (1998).

${ }^{62}$ F. Salver-Disma, J. M. Tarascon, C. Clinard, and J. N. Rouzaud, Carbon 37, 1941 (1999).

${ }^{63}$ J. Y. Huang, Acta Mater. 47, 1801 (1999).

${ }^{64}$ J. Y. Huang, H. Yasuda, and H. Mori, Chem. Phys. Lett. 303, 130 (1999).

${ }^{65}$ Y. Chen, J. F. Gerald, L. T. Chadderton, and L. Chaffron, Appl. Phys. Lett. 74, 2782 (1999)

${ }^{66}$ T. S. Ong and H. Yang, Carbon 38, 2077 (2000).

${ }^{67}$ X. H. Chen, H. S. Yang, G. T. Wu, M. Wang, F. M. Deng, X. B. Zhang, J. C. Peng, and W. Z. Li, J. Cryst. Growth 218, 57 (2000).

${ }^{68}$ S. Orimo, G. Majer, T. Fukunaga, A. Züttel, L. Schlapbach, and H. Fujii, Appl. Phys. Lett. 75, 3093 (1999).

${ }^{69}$ T. Fukunaga, K. Itoh, S. Orimo, M. Aoki, and H. Fujii, J. Alloy Compd. (submitted).

${ }^{70}$ E. Tanabe, K. Yamada, Y. Kitano, S. Orimo, and H. Fujii (unpublished).

${ }^{71}$ S. Orimo, H. Fujii, and K. Ikeda, Acta Mater. 45, 331 (1997).

${ }^{72}$ S. Orimo, K. Ikeda, H. Fujii, S. Saruki, T. Fukunaga, A. Züttel, and L. Schlapbach, Acta Mater. 46, 4519 (1998).

${ }^{73}$ S. Orimo and H. Fujii, Intermetallics 6, 185 (1998); Appl. Phys. A: Mater. Sci. Process. 72, 167 (2001).

${ }^{74}$ R. J. Nemanich and S. A. Solin, Phys. Rev. B 20, 392 (1979).

${ }^{75}$ B. S. Elman, M. S. Dresselhaus, G. Dresselhaus, E. W. Maby, and H. Mazurek, Phys. Rev. B 24, 1027 (1981).

${ }^{76}$ M. Kitajima, K. Aoki, and M. Okada, J. Nucl. Mater. 149, 269 (1987).

${ }^{77}$ T. Tanabe, S. Muto, Y. Goto, and K. Niwase, J. Nucl. Mater. 175, 258 (1990).

${ }^{78}$ T. Tanabe, K. Niwase, N. Tsukuda, and E. Kuramoto, J. Nucl. Mater. 191-194, 330 (1992).

${ }^{79}$ F. Tuinstra and J. L. Koenig, J. Chem. Phys. 53, 1126 (1970).

${ }^{80}$ D. S. Knight and W. B. White, J. Mater. Res. 4, 385 (1989).

${ }^{81}$ K. Nakamura, M. Fujitsuka, and M. Kitajima, Phys. Rev. B 51, 12260 (1990)

${ }^{82}$ G. Katagiri, H. Ishida, and Y. Nitta, Proceedings of 8th International Meeting on Lithium Batteries, Nagoya, Japan, 1996, p. 12.

${ }^{83}$ C. Carpetis and W. Peschka, Int. J. Hydrogen Energy 5, 539 (1980).

${ }^{84}$ K. A. G. Amankwah, J. S. Noh, and J. A. Schwarz, Int. J. Hydrogen Energy 14, 437 (1989).

${ }^{85}$ R. Chahine and T. K. Bose, Int. J. Hydrogen Energy 19, 161 (1994).

${ }^{86}$ M. Nishikawa, M. Uetake, K. Tanaka, and T. Shiraishi, Fusion Technol. 28, 717 (1995).

${ }^{87}$ A. C. Dillon, T. Gennett, J. L. Alleman, K. M. Jones, P. A. Parilla, and M. J. Heben, Proceedings of the 2000 DOE/NREL Hydrogen Program Review, 8-10 May 2000.

${ }^{88} \mathrm{M}$. Hirscher et al., J. Alloys Compd. (in press).

${ }^{89}$ M. Hirscher et al., Appl. Phys. A: Mater. Sci. Process. 72, 129 (2001).

${ }^{90}$ A. R. Nyaiesh and W. B. Nowak, J. Vac. Sci. Technol. A 1, 308 (1983).

${ }^{91}$ J. Fink, Th. Müller-Heinzerling, J. Pflüger, B. Scheerer, B. Dischler, P. Koidl, A. Bubenzer, and R. E. Sah, Phys. Rev. B 30, 4713 (1984).

${ }^{92}$ J. Gonzalez-Hernandez, B. S. Chao, and D. A. Pawlik, J. Vac. Sci. Technol. A 7, 2332 (1989).

${ }^{93}$ R. B. Wright, R. Varma, and D. M. Gruen, J. Nucl. Mater. 63, 415 (1976).

${ }^{94}$ J. Robertson and E. P. O'Reilly, Phys. Rev. B 35, 2946 (1987).

${ }^{95}$ H. E. Kissinger, Anal. Chem. 29, 1702 (1957).

${ }^{96}$ N. Akuzawa, T. Sakamoto, H. Fujimoto, T. Kasuu, and Y. Takahashi, Synth. Met. 73, 41 (1995).

${ }^{97}$ K. Wakabayashi, M. Fujita, H. Ajiki, and M. Sigrist, Phys. Rev. B 59, 8271 (1999). 